\title{
Racionalización de la Harmonía. Reflexiones sobre música y número en la cosmología pitagórica
}

\author{
José Antonio Cervera \\ El Colegio de México, Centro de Estudios de Asia y África \\ jacervera@colmex.mx
}

Juan Carlos Sordo

Tecnológico de Monterrey, Campus Monterrey, departamento de Estudios Humanísticos, DHCS jc.sordo.phd.mty@itesm.mx

\section{Introducción}

A la postre, las matemáticas hunden sus raices en los mismos magmas simbólicos en que se alimentan los mitos que aspiraban a desplazar.

(Lizcano, 1993)

Indagar en el origen de la Racionalidad que se supone universal, incontrovertible, matemáticamente demostrable, y que sigue caracterizando buena parte del pensamiento cientificista occidental, puede parecer ya una tarea infructuosa. La reflexión filosófica en torno a la ciencia, desde mediados del siglo XX, ha hecho tambalear una noción tal y ha mostrado que grandes dosis de «irracionalidad» han contribuido en su construcción. A pesar de ello, el conocimiento matemático sigue considerándose en gran medida ajeno a dichos cues- 
tionamientos y, por tanto, el garante de la neutralidad y la objetividad científicas.

Los pasajes históricos decisivos en el desarrollo de esta noción de Racionalidad, incluso los referidos a la evolución del pensamiento matemático, suelen implicar conflictos entre hombres concretos y sus formas de comprender el mundo. Estudiarlos, atendiendo a diversas dimensiones de lo que en ellos se encontraba en liza, puede desplegar interesantes cuestiones implicadas en la forma en que se dio su resolución. Puede mostrar de ahí su valor, qué fue aquello que quedó excluido de la Razón tras su nueva formulación.

Consideraremos uno de esos pasajes específicos: la postulación pitagórica de una harmonía ${ }^{1}$ universal. Su relevancia en la historia de la Racionalidad occidental y particularmente en el establecimiento de sus fundamentos matemáticos es manifiesta. Sostener que es posible establecer, tras la apariencia de los fenómenos, relaciones entre números enteros que supondrían su verdad más esencial, supuso una verdadera revolución epistemológica y ontológica. Además, se derivó de ello un doble sentido de la palabra «irracional»: por una parte, se refiere a la imposibilidad de establecer dicha «razón» o relación numérica y, por la otra, representa un atentado contra la idea de un universo ordenado y la posibilidad de conocer las leyes que lo rigen.

Es bien conocida la anécdota de que los pitagóricos, al descubrir la irracionalidad matemática entre las longitudes de la diagonal y el lado de un cuadrado, decidieron guardarla celosamente en secreto. Si bien la superación de su fetichismo

1 Según el diccionario de la Real Academia Española de la lengua (edición 22ª), se puede escribir indistintamente «armonía» y «harmonía». Hemos preferido la segunda forma, para enfatizar la antigua acepción, que se fue perdiendo en Occidente desde la época de los pitagóricos. 
hacia los números enteros volvería inofensivo dicho descubrimiento, el otro costado de la irracionalidad, es decir, el no ajustarse a una concepción unitaria de la realidad con fundamentos inteligibles, permanecería como parte esencial de la Racionalidad hasta nuestros días. Pero esta irracionalidad numerológica sería encontrada (y ocultada) por los pitagóricos también en otro sitio: en el tono completo del intervalo musical (Levin 2009; 7)². Con ello, no sólo su concepción del número, sino también la relación que establecieron entre éste y la música, fundamental para su cosmología y para los alcances de su pensamiento, era seriamente cuestionada. Es a esta relación, a la forma de comprenderla y a las conclusiones de ella extraídas, a lo que se refieren particularmente las reflexiones del presente artículo.

\section{Música y número}

Al estudiar la vida y el pensamiento de Pitágoras, la historia, el mito y la leyenda se entretejen. La falta de registros escritos directos, por el principio de secrecía que reinaba en el interior de su secta, y la distancia temporal que separa los hechos de los autores posteriores que los registran, hacen que sus referencias sean vagas e inconsistentes en muchos aspectos ${ }^{3}$.

2 La diferencia entre la quinta y la cuarta corresponde a la relación 9:8, que al dividirse no arroja dos números enteros sino 3:2 $\sqrt{2}$.

3 La búsqueda que realizan Kirk, Raven y Schofield sobre testimonios antiguos en torno a Pitágoras y sus seguidores son contradictoras en la imagen del maestro de Samos, llegándose a dudar de su reputación de sabio y dejando entrever fuertes tensiones y animadversión en torno al grupo que formara, relacionadas con la creciente actividad política de sus miembros. Más allá de esas controversias, en lo referente a las aportaciones matemáticas que se le atribuyen existe abundante información en libros de historia de las matemáticas, tales como Boyer 1991, 47-57 y 70-71; Kline1992, 53-61 (edición en inglés: 1972); Collette 1998, $72-89$ (edición en francés: 1973); Struik 2002, 57-61 (edición en inglés: 1948). 
Aun así, parece fuera de controversia que alrededor del paso del siglo VI al V a.n.e. los pitagóricos sostenían ya la idea de que las relaciones entre números enteros -especialmente entre los que formaban la «tetractýs» ${ }^{4}(1,2,3$ y 4$)$ - resultaban harmoniosas; que, por lo tanto, constituían la vía de acceso al conocimiento de todas las cosas, y con ello también a cierta pureza o elevación del alma.

Dios es la unidad, el mundo, la pluralidad que contiene los elementos contrarios. La armonía restaura la unidad con las partes y las moldea en el cosmos. La armonía es divina, consiste en relaciones numéricas. El que llega a comprender la armonía en términos de números se vuelve divino e inmortal (Collette 1998; 73).

Parece también fuera de toda controversia que los pitagóricos fundaban (o pretendían fundar) la validez de dicha concepción en experimentos acústicos. La anécdota se encuentra ampliamente difundida. Supuestamente habría sido el mismo Pitágoras quien, experimentando con cuerdas iguales e igualmente tensadas, encontró que la altura del sonido que emiten al ser pulsadas se relaciona directamente con su longitud ${ }^{5}$. Descubriría a partir de ello que las combinaciones sonoras harmoniosas respondían con la posibilidad de comparar las longitudes como relaciones entre números enteros. Su asombro le llevó «a concluir que las razones de los números enteros explican, rigen, más aún, producen los fenómenos de la naturaleza» (Sestier 1989; 27) y que es en esas relaciones numéricas harmoniosas en las que

$4 \quad$ Figura triangular a la que se le otorgaba significado místico, formada por 10 puntos distribuidos en cuatro hileras, con uno, dos, tres y cuatro respectivamente.

5 En relación al sonido de una cuerda de longitud $x, x / 2$ y $2 x / 3$ corresponderán respectivamente a la octava y la quinta. 
se fundamenta el orden del universo, es decir, la realidad como «cosmos», más allá de las apariencias caóticas que generalmente se nos presentan.

Dichas nociones implican las particulares concepciones numéricas de los pitagóricos, quienes dotaban a los números enteros de existencia material conformadora de los objetos, de donde derivaba la gravedad del conflicto que significaba la «irracionalidad» (o «inconmensurabilidad»). Esta forma de entender los números como realmente presentes en la naturaleza, los llevó a desarrollar una serie de consideraciones de carácter místico o religioso con respecto a ellos, a partir de doctrinas de origen oriental. En éstas era fundamental el estudio de las configuraciones geométricas que se podían trazar al disponer las unidades de que se conforma un número como puntos discontinuos.

El carácter intuitivo y figurativo de su trato de los números ha llevado a denunciar que no se halla netamente presente en ellos una mentalidad matemática en el sentido moderno, sino más bien una suerte de «aritmología» o «aritmomancia» (Eggers y Juliá 2000; 228-229). En todo caso, los méritos de los pitagóricos en este ámbito son indudables. Se considera que introdujeron la necesidad de las demostraciones rigurosas en matemáticas (Rey Pastor y Babini 1951; 23), -aunque paradójicamente se considere como su mayor logro el descubrimiento de la irracionalidad-; asimismo, su pensamiento cosmológico representa uno de los más tempranos y fuertes impulsos dados a la idea de que la verdad de la naturaleza es inteligible y puede ser alcanzada a través del descubrimiento de las relaciones matemáticas que la rigen.

Sin embargo, si desde una perspectiva actual los excesos en su tratamiento de los números se consideran excusables por las limitaciones de su conocimiento matemático, el juicio 
que se hace de la reverencia mantenida hacia la música en la cosmología pitagórica es, sin embargo, mucho más severo. Su concepción musical ha pasado a ser tomada como un residuo de misticismo en la racionalidad científico-matemática incipiente que obstaculizó su pleno desarrollo; y su formulación más difundida, la referencia a una imperceptible música de las esferas celestes, tiende a ser reducida a una vergonzosa desviación del andar decididamente progresivo del pensamiento occidental. Bell lo expresa de la siguiente manera:

La ley pitagórica fue la responsable de la retención de la 'música' en la enseñanza medieval. De hecho, del descubrimiento de que el sonido musical y los números podían relacionarse se extrajo cualquier consecuencia que pueda concebirse, excepto una que resulte sensata desde un punto de vista moderno [...] el experimento que pudo haber sido el inicio de una era científica [...] contribuyó efectivamente a retardarla por 2000 años (Bell 1945; 50).

¿No valdría acaso la pena llevar a cabo una consideración más sosegada de un asunto que resultó fundamental para el desarrollo del pensamiento racional matemático, que significó siglos en que música y matemáticas se hicieron compañía en la enseñanza formal del quadrivium ${ }^{6}$ y que jugó un papel inequívoco en las elaboraciones de científicos de la talla de Johannes Kepler? Realicemos un esfuerzo por abandonar nuestra perspectiva actual para aproximarnos al mundo en que dichas ideas se desarrollaron; tratemos de colocarnos

6 «Los cuántos, es decir la cantidad discreta, podía a su vez estudiarse en sí (aritmética) o bien en relación con otra (música), mientras que, por su parte, el cuánto, es decir, la cantidad continua, podía estudiarse fija (geometría) o móvil (astronomía), llegándose a la clasificación del saber en el clásico quadrivium latino que se mantuvo en la enseñanza durante dos milenios» (Rey Pastori y Babini 1951; 22). 
en los zapatos, o mejor, en los oídos, en la sensibilidad de aquellos hombres. ¿Qué pudo significar para ellos el descubrimiento del vínculo entre la música y los números? La atención detallada a ciertos elementos históricos y culturales puede revelar una realidad muy distinta a la que se toma por dada. Sobre todo, podría contribuir al esclarecimiento de por qué fue necesaria la música en el pensamiento pitagórico, cuál fue el papel que en él jugó, y por qué sus figuraciones numéricas no se bastaban a sí mismas para ser aceptadas por filósofos y científicos posteriores como develadoras de los secretos del universo.

\section{Organización prepitagórica de la experiencia}

Comencemos por aproximarnos al pensamiento prepitagóri$\mathrm{co}$, para poder así sopesar con mayor exactitud la verdadera revolución intelectual que significó la formulación de la noción de la harmonía universal. Algunas ideas del filósofo de la ciencia Paul Feyerabend pueden resultar, para tal efecto, una guía adecuada. Partiendo de su planteamiento, que considera posibles distintas formas coherentes y estables de organizar la experiencia y la realidad, presenta en un capítulo de su Tratado contra el método un estudio de la manera particular en que esta organización era llevada a cabo en la Grecia homérica. A través de un análisis de tipo gramatical-sintáctico de la forma en que se representaban las figuras -particularmente la figura humana- en la pintura de la cerámica de la época, así como en algunos fragmentos de poemas homéricos, encuentra constantes estructurales que ofrecen claves sobre un «estilo cognitivo» particular y consistente.

Según Feyerabend, en las pinturas las partes del cuerpo se agregan unas a otras para conformar la representación de 
un hombre. La posición se suma, sin modificar la disposición de las partes del cuerpo. Tampoco se recurre a la perspectiva. En los poemas homéricos, las circunstancias, títulos personales, explicaciones, etc., todo ello se suma al conjunto total para conformar la representación humana. No existen oraciones subordinadas, se coloca simplemente una tras otra. Nos encontramos, por lo tanto, ante una cosmovisiónorganización de la realidad que se da de forma paratáctica, es decir, a modo de elementos que sólo se adicionan unos a otros. «El conocimiento completo de un objeto es la completa enumeración de sus partes y sus peculiaridades [...]. Pero aunque el hombre no puede tener conocimiento completo, sí puede tener una cierta magnitud de éste» (Feyerabend 1975; 261). Ante este estado de cosas, las distintas ideas sobre la naturaleza y la realidad, aunque diferentes, podían convivir unas con otras sin que fuera necesario buscar una verdad unificada y sin que el «caos» que de ello resultara, impidiera el desarrollo de la vida práctica. Las diferentes opiniones de los sabios y los pensadores antiguos consignadas por Platón en muchos de sus diálogos dan una clara muestra de ello.

Ahora bien, a esta concepción, los pitagóricos opondrían la ley de la harmonía universal. Según su visión, el «orden» sería la esencia de todas las cosas existentes y la naturaleza de ese orden sería única y divina.

\section{Música y musicalidad en la antigua Grecia}

Hemos descrito la era prepitagórica u homérica como una en la que primaba la organización paratáctica de los elementos de la experiencia o de la realidad. Sin embargo, en la breve descripción que presentamos, hemos omitido referirnos al lugar que ocupaba la música en ese mundo antiguo. La 
música, sin embargo, era entonces revestida de características particulares. Se le atribuían poderes mágicos de encantamiento, la capacidad de subvertir las leyes naturales o de unificar principios opuestos. Su capacidad de afectar el alma humana, tanto de edificarla como de corromperla, llevaría a Platón a considerar fundamental su vigilancia por parte del Estado y a Aristóteles a elaborar en términos psicologizantes dicho potencial. Según Benedito, «desde los comienzos del desarrollo de su cultura los griegos consideraron que la música era un poderoso medio de acción que intervenía decisivamente en el orden religioso, moral, político y social» (2007; 408).

Flora Levin refiere, además de la existencia de un acompañamiento musical de prácticamente todas las actividades sociales, un carácter de la musicalidad del mundo griego pocas veces aludido. Se trata del acento tonal de su lengua antigua en que el significado de las palabras depende también del tono en el que son vocalizadas las sílabas, haciendo de la lengua común una «expresión melodiosa» $(2009 ; 12)$ y condicionando el oído de sus hablantes a una gran capacidad de discernimiento de sutiles diferencias acústicas ${ }^{7}$.

Es en ese marco en el que debemos aproximarnos al papel de la harmonía musical en su capacidad de ordenamiento del mundo, teniendo en cuenta un dominio de percepciones auditivas difícilmente imaginable desde nuestra perspectiva. Esto implica, por una parte, su capacidad de afectar el alma de quien la escucha, rasgo fundamental en la concepción desarrollada por los pitagóricos, pero también ofrece la posibilidad de dotar a los elementos de la experiencia, de

$7 \quad$ Algo similar a lo que sigue ocurriendo en algunas lenguas tonales orientales, como el chino. 
otra forma aislados o solamente agregados unos a otros, de una organización estética y perceptiva superior alcanzada entonces sólo a través del oído y la sonoridad.

La harmonía musical se hallaría así revestida de cualidades de las que hasta entonces gozaba exclusivamente y que le otorgaban, a quien la experimentaba, una sensación de orden y coordinación de distintos elementos, difícilmente experimentados por otras vías. Habría por lo tanto, en la concepción griega de la música, además de los elementos míticos, místicos y mágicos de la tradición más antigua, las condiciones que llevaron a los griegos, según las palabras de Levin, a ser:

Los primeros en intuir la esencia de la música, y los primeros en descubrir las leyes que gobiernan su estructura. Ellos fueron los primeros en percibir los elementos de la música no como entidades aisladas desarticuladas unas de otras sino como partes integrales de un todo orgánico del que cada parte deriva su sentido y posición (Levin $2009 ; 16)^{8}$.

5. Visualizando el sonido o aprehendiendo la harmonía

Hemos intentado mostrar que, fuera del ámbito musical, prácticamente no existía en el mundo griego antiguo la noción de harmonía. El descubrimiento pitagórico que lograba ligarla con los números enteros, y a través de ellos, con el resto de los objetos del cosmos, supondría una ampliación de sus alcances hacia realidades no musicales y hacia fenómenos no auditivos, lo que puede considerarse una verda-

8 La misma Levin, sin embargo, aclara a lo largo de su trabajo que no sería la interpretación pitagórica la que mejor encarnaría estos logros. 
dera revolución cognitiva. Consideremos ahora lo que ello implicó.

La atención al quadrivium da cuenta de la función del entrenamiento musical dentro de la formación que se originó en la enseñanza pitagórica. En ella, la música, o más precisamente la harmonía, era considerada una parte de la matemática, aquella en la que se estudia la relación entre cantidades discretas (o entre números enteros). Así, la harmonía de la relación entre los números no era algo que pudiera ser percibido directamente sino que debía aprenderse, para lo cual se utilizaba el instrumento más simple posible: el monocordio. Dicho entrenamiento constituía la primera posibilidad de acceder a una representación visual del sonido y, con ello, a una nueva forma de manipulación y comprensión de las cualidades acústicas y musicales (Moy 2000; 14) ${ }^{9}$.

Sin embargo, de las cuatro categorías en que los pitagóricos dividían las matemáticas (aritmética, harmonía, geometría y astronomía), desarrollaron particularmente la aritmética y la geometría, es decir, la ciencia de los «cuántos» y el «cuánto» considerado de forma estática y no dinámica (Rey Pastor y Babini 1951; 22). El concepto de «harmonía», fundamental en la doctrina pitagórica y en su pensamiento matemático-científico, fue cada vez más interpretado en términos de relaciones estáticas entre longitudes observables, alejándose de su origen sensorial acústico.

Como ya se señalaba, también en este ámbito los pitagóricos habrían de encontrarse con el problema de la inconmensurabilidad. Intervalos musicales que resultaban

9 Según Moy, esto constituye el inicio del establecimiento de códigos visuales-matemáticos o sistemas de notación musical que determinan lo que es música y lo que es ruido. 
harmónicos al oído no correspondían exactamente a su expresión en términos de la relación entre dos números enteros. La actitud ante dicha dificultad fue, al igual que en el caso de la inconmensurabilidad entre la diagonal del cuadrado y su lado, ignorarla y conservar las consecuencias extraídas de la supuesta correspondencia exacta. De esta forma, se introdujo ad hoc lo que se denominó la «comma pitagórica», un pequeño valor que debía agregarse para salvar la distancia entre lo calculado y lo percibido. Así, mientras se extendía el principio de la harmonía universal a todos los ámbitos de la naturaleza, las elaboraciones matemáticas eran consideradas como más reales que las experiencias de escucha en las que pretendían sostenerse. En Platón, esta tendencia llegaría a cristalizar uno de los más importantes difusores del pitagorismo, en una concepción de la música como aspecto fundamental en el cultivo del alma y en el acceso al conocimiento pero completamente desdeñosa de la escucha. Fubini sintetiza dicha concepción de la siguiente manera:

Hay por consiguiente, una música que se oye y otra que no se oye; únicamente esta segunda música -la que no se oye- es digna de la atención del filósofo. Más aún: la meditación sobre esta música abstraída de la sonoridad es un filosofar y, tal vez, el más alto grado de filosofar (1999; 66).

Ahora bien, para la noción de harmonía musical, el elemento temporal era fundamental. La forma de lograrla descansaba en la disposición sucesiva de los sonidos, lo que generalmente se realizaba a modo de improvisaciones a partir de ciertos convencionalismos provenientes de las tradiciones musicales no escritas ni teorizadas. Como señala Benedito: 
La ordenación «harmoniosa» de los sonidos es lo que entendían los griegos por «harmonía» [...]. El concepto de armonía como audición de varios sonidos simultáneos que producen un acorde es mucho más moderno [que] ese sentido griego de ordenación sucesiva de sonidos $(2007 ; 412-313)$.

¿Cómo es entonces que sus concepciones matemáticas sobre la música pudieron dar lugar a una concepción no dinámica de la harmonía? ¿Cómo dejó ésta de considerarse un asunto localizado en el transcurrir del tiempo, una forma de la sucesión? ¿Cómo es que la teoría musical pitagórica llegó a divorciarse del oído?

6. Acusmáticos y matemáticos.

Controvertidas designaciones

La respuesta a las cuestiones recién planteadas quizás no pueda encontrarse en un nivel epistemológico neutral. Ha de ser necesario considerar los intereses, las pugnas políticas, la descalificación. Las limitaciones ya señaladas de las fuentes escritas impiden una reconstrucción definitiva satisfactoria; sin embargo, ofrecen suficientes elementos para mostrar algunas particularidades de este pasaje histórico que han sido escasamente consideradas.

Algo es indudable: en la secta pitagórica existía la división. La distinción más difundida es la de pitagóricos «matemáticos» y «acusmáticos», y las referencias a dicha distinción consignan siempre entre ambos grupos cierto grado de confrontación. Las primeras complicaciones para comprender esta división derivan de la utilización actual de los términos, en la que la designación «acusmáticos» ha caído práctica- 
mente en desuso ${ }^{10}$ y el sentido dado al concepto «matemáticos» difiere ampliamente del que poseía entonces. A éstas va a unirse una serie de inconsistencias e interpretaciones que consideramos incorrectas, lo cual se busca mostrar con este trabajo. Habría que partir de la advertencia que Eggers y Juliá presentan en una nota:

La división entre pitagóricos «acusmáticos» y «matemáticos» no debe datar del tiempo de Pitágoras, aunque de entonces puede haber derivado una diferenciación natural entre los más antiguos $-\mathrm{y}$, por ende, que más habían aprendido- y los novatos, o bien entre los dedicados a la praxis y los consagrados a la teoría. Sólo hacia fines del siglo $\mathrm{V}$ a. C. la división podría haberse convertido en dos tendencias enfrentadas. Pero las denominaciones no son anteriores al siglo IV, y en ningún caso la de «matemáticos» alude a las Matemáticas (2000; 225).

En las diferentes referencias antiguas la división respondería a la antigüedad del discípulo o, como veremos más adelante, al estadio en el que se encontraba en su formación. Sin embargo, algunos autores, y con mayor claridad conforme más distanciados temporalmente se encontraban, iban definiendo la separación entre las dos clases en términos de una mayor o menor capacidad intelectual, ya como distintos grados en la profundidad de su conocimiento e incluso como una separación entre seguidores acríticos puramente religiosos y los herederos de un supuesto espíritu científico.

La mayoría de las fuentes coincidirán en que los «acusmáticos» eran, en el mejor de los casos, los principiantes, o

10 A excepción de la llamada música «acusmática», aquella en cuya difusión se elimina cualquier referencia visual a la fuente del sonido. 
en la interpretación menos favorable, aquellos no interesados o incapaces de comprender las profundas verdades descubiertas, por lo que deberían confiar en la veracidad de lo que les era revelado. La designación de «acusmáticos», sin embargo, no hace referencia necesariamente a la constitución de un grupo específico de pitagóricos, sino que deriva de acusmata, es decir, «cosas oídas», nombre dado a las máximas transmitidas oralmente que se considera formaban parte de la doctrina pitagórica y que pueden dividirse en reglas de abstinencia, prohibiciones de otros tipos y las específicamente referidas al número y la harmonía (Kirk et al., 2008; 307-311). La irracionalidad -en sentido moderno-que se atribuye a los «acusmáticos» consistiría en que supuestamente seguían acríticamente las reglas de abstinencia y prohibiciones, muchas de las cuales se consideran simples supersticiones sin sentido ni fundamento, mientras que «matemáticos» serían aquellos que accedían a dichas demostraciones y a su comprensión.

Sin embargo, aunque las caracterizaciones de cada uno de estos grupos se han ido generalizando en el sentido recién expuesto, lo cierto es que existen fuertes dificultades para aceptar sin cuestionamientos esa distinción simple. La confusión comienza muy pronto. Jámblico, una de las principales referencias de la distinción «acusmáticos-matemáticos», es inconsistente y contradictorio en sus afirmaciones. La exactitud de la información presentada por Jámblico es cuestionada por Kirk et al., que consideran su trabajo sobre los pitagóricos como producto de un «picoteo» realizado en diversas fuentes históricas, de algunas de las cuales incluso se ha cuestionado su autenticidad (Hernández 2011; 121135). Lamentablemente, él se convierte a su vez en la fuente de muchas de las referencias posteriores. 
De esas inconsistencias en la obra de Jámblico nos resultan especialmente relevantes las que se dan en torno a un personaje controvertido: Hipaso de Metaponto (ca. 530¿450?). No solamente lo coloca alternativamente en uno y otro grupo, sino que además lo considera el descubridor de la inconmensurabilidad. Los mismos Kirk et al. ponen en seria duda esta atribución a Hipaso. Sin embargo, el implicarlo en dicho descubrimiento o al menos en su difusión, lo que la secta pitagórica celosamente había evitado, lo coloca como una figura central en este asunto. También se le vincula con experimentos acústicos, lo que señalaría al menos su interés en la materia, y lo que, aventuramos, guardaría relación con su postura incómoda dentro del grupo, pues por más que las dudas respecto a su persona no puedan ser totalmente despejadas, resulta evidente que fue considerado como uno de los personajes centrales en el conflicto intergrupal de los pitagóricos y en torno a cuál era el verdadero pitagorismo. Vale la pena recordar, como ya se mencionaba, que el mismo problema de la inconmensurabilidad de la diagonal del cuadrado se presentaba en la ciencia acústica respecto al tono completo.

El asunto se complica aún más si consideramos que Hipaso pudo haber muerto poco después de la polémica del descubrimiento o divulgación de la inconmensurabilidad. Aunque aquí también las versiones son diversas: unos atribuyen su muerte a un castigo divino, otros señalan que simplemente los pitagóricos lo expulsaron y le levantaron una tumba, simbolizando que para ellos había muerto; pero se ha llegado a conjeturar que podría haber sido realmente asesinado. Altieri, a partir de Jámblico, también refiere que Hipaso fue «uno de los que iniciaron la rebelión contra los pitagóricos» y agrega que los rebeldes «sostenían que debía 
concederse a todos el derecho de participar en las asambleas y de ser elegidos a los cargos públicos» (1986; 55), vinculándolo de esta manera también a la problemática política en la que se vieron involucrados por la gran injerencia alcanzada por los pitagóricos en la administración de diversas ciudades y la forma excluyente en que se conducían como secta.

De aquí surge la hipótesis que ha generado la investigación que aquí se presenta: el sentido que va tomando esta distinción entre dos clases de pitagóricos ha sido influido por el desenlace de un conflicto intergrupal con una muy relevante dimensión política. Seguramente existían también divergencias entre las formas en que se concebía el acceso al conocimiento y la manera en que el filósofo debe procurarlo. Por lo ya referido, en este sentido, un punto fundamental consistiría en determinar la naturaleza y el origen de la harmonía y, al mismo tiempo, si las relaciones numéricas y la racionalidad que de ellas se desprende son realmente harmónicas. Consideramos pues que este último asunto no fue resuelto sino ignorado por el pensamiento pitagórico que prevaleció.

\section{Matemáticos: desaprendiendo a escuchar}

Desarrollemos ahora una concepción alternativa sobre el origen de la distinción entre «acusmáticos» $\mathrm{y}$ «matemáticos», considerando no una distinción entre capacidad o incapacidad para conocer, sino entre preferencias por la forma de acceder al conocimiento. Aun cuando la caracterización que de cada uno de ellos hace puede estar influenciada por una perspectiva contemporánea, Horky reconoce que lo que los distingue fundamentalmente es su respectiva pragmateia, es decir «tanto el objeto de la investigación filosófica como el tratamiento de ese objeto» $(2010 ; 3)$, y además lleva a cabo un 
análisis sobre la relación entre cuestiones políticas y filosóficas implicadas en la división entre grupos pitagóricos que coincide parcialmente con la que aquí presentamos.

En su origen, la distinción entre grupos podría provenir de la ya citada antigüedad en su formación. Eggers y Juliá, basados en el Timeo, informan de un largo noviciado dentro de la enseñanza pitagórica del que, con mucha probabilidad, formaba parte el aprendizaje de los acusmata (2000; 226-227). Pierce -quien también critica fuertemente la veracidad de la obra de Jámblico-, al referirse a una forma particular de enseñanza «acusmática» a partir de la Vida de Pitágoras de Porfirio, subraya un rasgo fundamental para comprender lo que pudo haber constituido originariamente un pitagorismo de corte acusmático. Señala que los acusmáticos «de ordinario no veían el rostro de Pitágoras. Éste les hablaba desde detrás de un velo [...] una práctica tomada en préstamo de algunos misterios; se la continúa utilizando en la Iglesia Griega hoy en día» (Pierce, 2007). La enseñanza en aquel periodo podría buscar entonces no necesariamente transmitir conocimientos sin mostrar cuáles eran sus fundamentos, sino focalizarse en el oído, desarrollarlo, enseñar a escuchar atentamente.

La presentación que Maynadé hace de la formación en el instituto pitagórico, más allá de su visión excesivamente utópica, rescata detalles concretos de las actividades y las etapas de la enseñanza a partir de las referencias de Porfirio, Jámblico, Plutarco, Platón, Aristóteles, Herodoto y Laercio. En ella destaca el lugar central que poseían canto, música y danza; pero, de forma aún más relevante, muestra cómo en la primera etapa, que ella designa precisamente como la de los «acusmáticos», lo fundamental no era la exclusión de los discípulos de la enseñanza avanzada, que tras un tiempo podían presenciar, sino su largo y riguroso entrenamiento en 
el silencio. Lo que les estaba vedado no serían por tanto las demostraciones matemáticas o las razones del conocimiento, sino el poder participar con su palabra en las discusiones. Maynadé interpreta así el sentido de esta práctica:

A través del hábito del silencio, aprende el pitagórico a escuchar. Primero las palabras, luego las vibraciones. [...] Todo habla al que es capaz de escuchar y comprender. [...] Todo consiste en saber hallar esta armonía. [Tras ello] emplearéis el lenguaje como un afinado instrumento armonioso. Sólo así penetrarán vuestras palabras en el alma de los que os escuchen. Así crearéis con ellas música de pensamiento $(1969 ; 149-150)$.

Consideremos así un escenario que resulta plausible con lo hasta ahora expuesto. Al mismo tiempo que el poder político que la secta pitagórica detentaba en la administración de diversas ciudades era cada vez mayor, al haber crecido el número de sus miembros, la probabilidad de ejercer dicho poder para un miembro específico era cada vez más reducida. Surgirían así conflictos internos y distintas facciones. Los posteriormente denominados «matemáticos» lograrían hacerse del poder y se presentarían a sí mismos como los verdaderos seguidores del camino iniciado por Pitágoras. Como resultado, impondrían su interpretación del pitagorismo como el genuino sentido del pensamiento de su maestro, considerando al resto como discípulos de segunda categoría. Uno de los asuntos que se encontraría en liza en la oposición de las facciones sería esa concepción de la harmonía y particularmente su forma de acceder a ella.

Recurrir al origen etimológico de la palabra matemáticas puede resultar ahora esclarecedor. «Matemáticas», en griego $\mu \alpha \theta \eta \mu \alpha \tau$ เx́, «las cosas que se aprenden», proviene de 


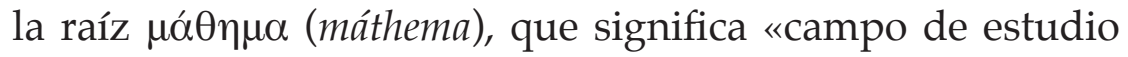
o instrucción». Curiosamente, su sentido es contrapuesto a

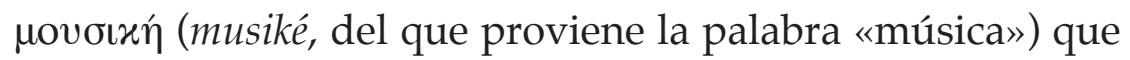
significa «lo que se puede entender sin haber sido instruido».

Los «matemáticos», más que distinguirse por otorgar una primacía a las matemáticas en sentido moderno, privilegiarían el conocimiento al que se accede por instrucción y por el conocimiento de sus causas, reduciéndose el papel de la escucha. La harmonía matemática, y con ella la verdad de las cosas, habría de ser descubierta activamente, pues no se presentaba ya dada a quien solamente sería capaz de escucharla. Por el contrario, había que investigar, había que instruirse, había que recurrir a la demostración, aquello que pone en juego antes la representación visual y las construcciones geométricas que la inmaterialidad de lo sonoro. El conocimiento verdadero, el acceso a la harmonía del cosmos, quedaría así vedado para las mayorías y sería privilegio sólo de un grupo selecto.

Por su parte, los «acusmáticos», o los posteriormente así llamados, serían quienes daban primacía a la experiencia musical en el acceso a la harmonía y que cuestionaban la posibilidad de aprenderla por medios no acústicos, al menos sin una preparación previa del oído y la sensibilidad. Considerarían entonces la etapa de silencio y el entrenamiento de la capacidad de escucha como la cuestión fundamental de la enseñanza pitagórica y de la posibilidad de hacer acceder a la experiencia harmónica, lo que de otra forma sólo constituiría una serie de elementos agregados. Para ellos, sólo el oído podría descubrir la harmonía, y los números entendidos como elementos materiales o, más exactamente, las figuras con ellas formados, sólo serían una representación de aquélla. 


\section{Aristóxeno: una denuncia teórica}

Aristóxeno (ca. 375- ca. 300 a.n.e.) es un personaje extrañamente poco conocido. Fue discípulo de Aristóteles, pero mantuvo antes contacto de primera mano con los pitagóricos de la última generación, teniendo por maestro a Xenófilo. Escribió cuatro trabajos sobre el pitagorismo, y aunque ninguno se conserva intacto (Huffman 2010), la cercanía le confiere mayor autoridad que a autores más tardíos influidos por la interpretación platónica. Resulta así relevante que atribuya no a Pitágoras sino a Hipaso la demostración física de que las relaciones musicales podían representarse mediante razones numéricas. Kirk et al., quienes presentan esta referencia, añaden que «es probable que el conflicto testimonial en este punto tenga relación con una antigua división de opiniones entre los pitagóricos respecto al origen del elemento científico o teórico de su tradición» $(2008 ; 312-313)^{11}$, para posteriormente introducir la distinción entre 'matemáticos' y 'acusmáticos', la cual no se encuentra en los escritos de Aristóxeno.

Aristóxeno resulta relevante en las cuestiones discutidas en este trabajo por haberse dedicado principalmente a la teoría musical. Mientras su retrato del pitagorismo es benévolo en otros aspectos, al tratarse de concepciones musicales su postura es abiertamente opuesta a éste. Aunque como referente histórico del pensamiento musical en la Grecia clásica su figura es eclipsada por la de Pitágoras, Levin señala que en su época fue reconocido ampliamente, y solía acompañarse su nombre por el calificativo de «El Músico» (2009; 62). Contribuyó a su olvido que Euclides y Ptolomeo favorecie-

11 Las cursivas son nuestras. 
ran la teoría musical pitagórica en detrimento de la de Aristóxeno, a la que consideraban equivocada.

Apoyados en la presentación que hace Levin, mostraremos brevemente algunos puntos de discrepancia entre la teoría de Aristóxeno y la de los pitagóricos, que subrayan el progresivo distanciamiento entre esta última y la experiencia de la escucha. Una diferencia fundamental entre la postura pitagórica predominante respecto a la teoría musical y las concepciones de Aristóxeno radica en que para este último, las cuestiones deben ser juzgadas por el oído y el intelecto sin la mediación de la representación geométrica figurativa, pues es el oído el que decide la musicalidad de un sonido aun cuando no coincida con las indicaciones matemáticas que emergen de las teorías. Siguiendo a Aristóteles, se atuvo a la experiencia directa de sus sentidos como punto de partida para el desarrollo de sus ideas, lo que le mostró que la teoría pitagórica no lograba dar cuenta a través de sus recursos matemáticos, de las propiedades percibidas en la música.

Si bien su teoría musical no era extrapolable a otros fenómenos, como la teoría de la harmonía universal, sus fundamentos coinciden más estrechamente con la teoría musical contemporánea y le permitió resolver, en el ámbito exclusivamente musical, las dificultades de la irracionalidad que los pitagóricos prefirieron callar o ignorar. Elaboró para ello una concepción de las dimensiones espacial y temporal de la música, no compartidas con el resto del mundo físico, en las que la noción de continuidad, retomada de Aristóteles, resultaba primordial. Ello le permitió abordar el problema de la inconmensurabilidad a partir de la posibilidad de divisiones infinitas del continuo musical, lo cual no respondía al modelo pitagórico que consideraba los números en su carácter discreto, lo que según Levin anticipa la forma de apro- 
ximación al problema que se emplearía siglos después en la Acústica $(2009 ;$ 201).

Aristóxeno sostuvo que el rasgo característico de la música era la melodía, de la cual la harmonía representaba solamente uno de sus componentes. Así, su concepción musical era esencialmente dinámica y en ella «los intervalos entre las notas de la melodía son tan vitales como las notas mismas [pues es] entre las notas de la melodía que el movimiento de la melodía tiene lugar» (Levin 2009; 109). Para Aristóxeno, la nota percibida no es generada por la frecuencia de la vibración de las cuerdas considerada como un movimiento uniforme determinado solamente por su longitud y que en última instancia permitiría la observación visual de un aspecto del fenómeno auditivo, sino que aplica su concepto de movimiento, no a la vibración mecánica de los objetos materiales que producen el sonido, sino a los cambios que se perciben dentro del sonido musical mismo. Esto lo llevó a sostener que la frecuencia de tono de una nota sólo emerge tras la terminación del movimiento, esto es, que la voz -humana o de un instrumento musical- se «mueve mientras genera un intervalo, pero se detiene al generar una nota musical» (Levin 2009; 52).

A partir de su método, Aristóxeno llegó a conclusiones distintas a las establecidas por la aritmética pitagórica sobre las relaciones de magnitud entre los componentes de la melodía. Euclides y Ptolomeo lo consideraron acientífico por la confianza depositada en los datos extraídos de la percepción sensorial sin tener en cuenta la racionalidad matemática, por la subjetividad implicada en la valoración «de oído» que propone y que no permite establecer con certeza criterios neutrales de observación. Aristóxeno reconocía que su aproximación suponía necesariamente un oído entrena- 
do para discernir sutiles variaciones en las cualidades de los estímulos acústicos, sin preocuparse por que su teoría no encontrara aplicación fuera del ámbito específico de la música; por el contrario, ello respondería al carácter particular de la experiencia espacio-temporal de su escucha. Pero más allá de las implicaciones netamente musicales de la controversia entre Aristóxeno y los herederos del pitagorismo, ésta tiene alcances epistemológicos. En ella se revela una creciente desconfianza en la percepción auditiva que corre paralela a la identificación entre rigor en el estudio de los fenómenos, objetividad y demostración matemática.

Independientemente de la validez de las propuestas de Aristóxeno, su obra denuncia el privilegio que la concepción pitagórica de la misma fue dando a la dimensión visual en su intento por demostrar racionalmente la universalidad de la harmonía conforme fue distanciándose de los elementos religiosos y éticos de sus orígenes. Asimismo, muestra cómo en el proceso de ampliación de los alcances de la noción de harmonía como fundamento de la existencia de una ley matemática subyacente a todos los fenómenos, el pitagorismo resueltamente ignoró no solamente la actividad misma de la que esta noción se desprendía, sino también la dimensión perceptiva o estética, la única en que podía tener algún sentido hablar de ella. Benedito llega a afirmar por ello que «la teoría [llegó a estar] totalmente divorciada de la realidad de la música práctica» (2007; 422).

De esta manera, aunque Aristóxeno no aluda a la distinción entre grupos de pitagóricos, presentó elementos que apoyan la idea de que en su teoría musical, tal como era conocida hacia el siglo IV a.n.e., existía ya una subordinación de los datos provenientes de la experiencia auditiva a las demostraciones matemáticas y que éstas respondían más 
exactamente a la posibilidad de representación visual. Así, la racionalidad numérica que había sido investida de alcances universales gracias a su estrecha vinculación con la harmonía musical, daba ya la espalda a la escucha: esa harmonía ya no se escuchaba más, sólo se imaginaba.

\section{Conclusiones}

El recorrido realizado por el pensamiento de la Grecia antigua y clásica en torno a la relación entre la racionalidad matemática y la música muestra implicaciones heterogéneas. Ha permitido problematizar -sin llegar a resolverlas- algunas cuestiones epistemológicas, políticas e históricas que la determinaron, y contribuye a dar cuenta de manera más completa de la forma en que tuvo lugar esa temeraria apuesta por comprender la realidad que supuso tomarla por un todo ordenado por un código numérico harmónico. A partir de ello, la superstición y el fetichismo numerológico pitagóricos pueden ser considerados, no como residuos de formas de pensamiento superadas, sino como uno de los principales impulsos para emprender esa labor intelectual que se ha extendido por milenios y que denominamos 'matemáticas'. También el ocultamiento o la ceguera ante problemas de gran magnitud se han revelado, bajo ciertas circunstancias, favorables para el desarrollo del pensamiento matemático.

La distinción simplificadora entre «acusmáticos» $\mathrm{y}$ «matemáticos» no sólo ha sido puesta en entredicho. Articulada con una visión crítica del papel de la harmonía musical para el surgimiento y la aceptación de las concepciones pitagóricas en la Grecia clásica y en los siguientes siglos, permite atisbar la relevancia que la escucha pudo tener en los orígenes del pitagorismo, en su desarrollo temprano y, con 
cierto fundamento, considerar a los «acusmáticos» como los partidarios de su lugar primordial en la doctrina y la formación. Así mismo, se ha mostrado que en la caracterización que cada grupo fue adquiriendo con el paso del tiempo, los factores políticos debieron tener alguna participación.

Esta misma injerencia política puede, al menos parcialmente, considerarse implicada en una progresiva devaluación del sentido del oído en su consideración como fuente digna de conocimiento y, por consiguiente, en su segregación de la empresa de la racionalidad. Ello implica una seria limitación del espectro de las percepciones y las experiencias que contribuyen a la construcción de la realidad cuyos alcances se extienden ampliamente en el tiempo. El empobrecimiento que ello ha podido implicar para el pensamiento científico racional no puede ser determinado con certeza, sin embargo, la distancia aparentemente insalvable entre algunas de las consideraciones antiguas que hemos señalado sobre la música y su caracterización actual desde la perspectiva científica dominante, puede insinuar su magnitud.

En última instancia, es preciso consignar que la formulación matemático-racional de la harmonía propuesta por los pitagóricos significó la pérdida de sus cualidades originarias, las cuales eran eminentemente estéticas y ligadas a la sensibilidad auditiva. Permitió, por otra parte, legitimar y dar soporte a una interpretación del mundo que con el paso del tiempo ha confirmado un potencial sorprendente para explicar, ordenar y predecir la experiencia, pero cuya validez no podría haberse sostenido inicialmente por sí misma. Implicó pues una operación de dimensiones epistemológicas, pero también políticas y religiosas, consistente en pretender dotar a un procedimiento demostrativo de los alcances anímicos de una experiencia mística sensitiva. Para que el pensamien- 
to racional matemático fuera aceptado como fundamento del conocimiento más profundo de las cosas fue necesario el «rapto» de la harmonía, antes un regalo de las musas, en favor del elitismo y el sectarismo intelectual. 
Bibliografía

Altieri, A. (1986). Los presocráticos. Puebla: Universidad Autónoma de Puebla.

Bell, E. (1945). The Development of Mathematics. Nueva York: McGraw-Hill.

Benedito, R. (2007). Los ecos de la melodía universal y la música en la polis. J.L. González Recio. (ed.), Átomos, almas y estrellas. Estudios sobre la ciencia griega. Madrid: Plaza y Valdés.

Boyer, C. (1991). A History of Mathematics, Nueva York: John Wiley \& Sons.

Collette, J. P. (1998). Historia de las matemáticas, vol. I, Pilar González (trad.). México: Siglo XXI.

Collette, J. P. (1973). Histoire des mathématiques 1. Montréal: Éditions du renouveau pédagogique.

Eggers, C. y Juliá V. (2000). Los filósofos presocráticos, vol. 1. Madrid: Gredos.

Feyerabend, P. (1975). Against Method. Londres: Verso.

Fubini, E. (1999). La estética musical desde la antigüedad hasta el siglo XX. Carlos Guillermo Pérez de Aranda (trad.). Madrid: Alianza Editorial.

Fubini, E. (1976). L'estetica musicale dell'antichità al Settecento. Torino: Einaudi.

Fubini, E. (1964). L'estetica musicale dal Settecento a oggi. Torino: Einaudi.

Hernández, D. (2011). Pitágoras en el espejo falsario: Cuestiones de falsificación literaria en torno a la Carta de Lisis (Jambílico, Vit. Pyth. 17.75 y Diógenes Laercio, Vit. Phil. 8.42). J Martínez. (ed.), Falsificadores y falsarios en la Literatura Clásica. Madrid: Ediciones Clásicas. 
Horky, P. (2010). Aristotle's description of Mathematical Pythagoreanism in the $4^{\text {th }}$ Century BCE, Princeton/Stanford Working Papers in Classics, p. 3.

Huffman, C. (2010). Pythagoreanism. En Edward N. Zalta (ed.), Stanford Encyclopedia of Philosophy [en línea].

Kirk, G., Raven, J. \& Schofield, M. (1957). The Presocratic Philosophers. A Critical History with a Selection of Texts. Cambridge: Cambridge University Press.

Kirk, G., Raven, J. \& Schofield, M. (2008). Los filósofos presocráticos. Historia crítica con selección de textos, Jesús García Fernández (trad.). Madrid: Gredos.

Kline, M. (1972). Mathematical Thought from Ancient to Modern Times, Nueva York: Oxford University Press.

Kline, M. (1992). El pensamiento matemático de la Antigüedad a nuestros días, vol. 1, Mariano Martínez, Juan Tarrés \& Alfonso Casal (trads.). Madrid: Alianza Editorial.

Levin, F. (2009). Greek reflections on the nature of music. Cambridge: Cambridge University Press.

Lizcano, E. (1993). Imaginario colectivo y creación matemática.

La construcción social del número, el espacio y lo imposible en

China y Grecia. Barcelona: Gedisa.

Maynadé, J. (1969). La vida serena de Pitágoras. México: Orión. Moy, R. (2000). An Analysis of the Position and Status of Sound Ratio in Contemporary Society. Nueva York: The Edwin Mellen Press.

Rey, Pastor J. y Babini J. (1951). Historia de la matemática. Buenos Aires: Espasa-Calpe.

Pierce, C. (2007). Pitágoras-La crítica histórica alemana (sexta conferencia de las Lowell Lectures sobre History of Sciences), R. Narváez (trad.). Grupo de Estudios Peirceanos de la Universidad de Navarra [en línea].

Sestier, A. (1989). Historia de las matemáticas. México: Limusa. 
Struik, D. (1948). A Concise History of Mathematics, Nueva York: Dover Publications.

Struik, D. (2002). Historia concisa de las matemáticas, Pedro Lezama (trad.). México: IPN. 


\section{Resumen}

Este artículo representa un esfuerzo por comprender algunas de las implicaciones epistémicas introducidas en la racionalidad occidental por la formulación pitagórica de la harmonía en términos de razones numéricas. Se discute el papel que la música tuvo en el surgimiento de esa racionalidad, y el origen de la distinción entre pitagóricos acusmáticos y matemáticos es rastreado discutiendo su concepción más difundida. Finalmente son presentados algunos elementos de la teoría musical de Aristóxeno que se oponen directamente a la sostenida por los pitagóricos.

Palabras clave: Grecia, irracionalidad, pitagorismo, acusmáticos, matemáticos, Aristóxeno.

\section{Abstract}

This article represents an attempt to understand some of the epistemic implications introduced on Western rationality by the Pythagorean formulation of harmony in terms of numeric ratios. A discussion is conducted on the role that music played in the emergence of that rationality, and the origin of the distinction between acousmatic and mathematical Pythagoreans is traced debating its commonly accepted explanation. Finally, some elements of Aristoxenus musical theory, in direct opposition to that supported by the Pythagoreans, are presented.

Keywords: Greece, irrationality, Pythagorism, acousmatics, mathematical, Aristoxenus. 
